\title{
Vitamin D supplementation practice in Ireland: data from the Cork BASELINE birth cohort study
}

\author{
S. M. O’Donovan ${ }^{1}$, L. Tynan ${ }^{1}$, D. M. Murray ${ }^{2}$, J.O'B. Hourihane ${ }^{2}$, L. C. Kenny ${ }^{3}$, A. D. Irvine ${ }^{4,5}$ \\ and M. Kiely ${ }^{1}$ \\ ${ }^{1}$ Vitamin D Research Group, School of Food and Nutritional Science, ${ }^{2}$ Department of Paediatrics and Child Health, \\ ${ }^{3}$ Anu Research Centre, Department of Obstetrics and Gynaecology, University College Cork, ${ }^{4}$ Department of Clinical \\ Medicine, Trinity College, ${ }^{5}$ Department of Paediatric Dermatology, Our Lady's Children's Hospital, Dublin, Ireland
}

In May 2010, the Health Service Executive (HSE), officially endorsed the recommendations made by the Food Safety Authority of Ireland (FSAI) in 2007, that; 'all infants, 0-12 months, breast or formula-fed, should be given $5 \mu \mathrm{g}$ of vitamin D daily ${ }^{(1)}$, as an interim measure for the prevention of rickets. The aim of this study was to describe the level of compliance among infants in the Cork BASELINE birth cohort study with the vitamin D supplementation policy and to compare supplementation practice before and after HSE implementation of the policy.

A total of 1954 maternal-infant dyads were recruited to the study and infants were examined at day 2 and at 2, 6 and 12 months. Data extracted for the current analysis were vitamin D supplementation during pregnancy, breastfeeding and at 2, 6 and 12 months and infant feeding.

$12 \%$ (227) of postnatal visits were conducted during the year prior to HSE implementation of the policy. Within this subset, $21 \%$ of infants received a vitamin D-containing supplement at some stage during the first year and 4,11 and $11 \%$ were provided with a supplement at 2, 6 and 12 months, respectively. After implementation, 76\% of infants received supplemental vitamin D and 49, 64 and $44 \%$ of infants were supplemented at 2, 6 and 12 months, respectively, see figure.

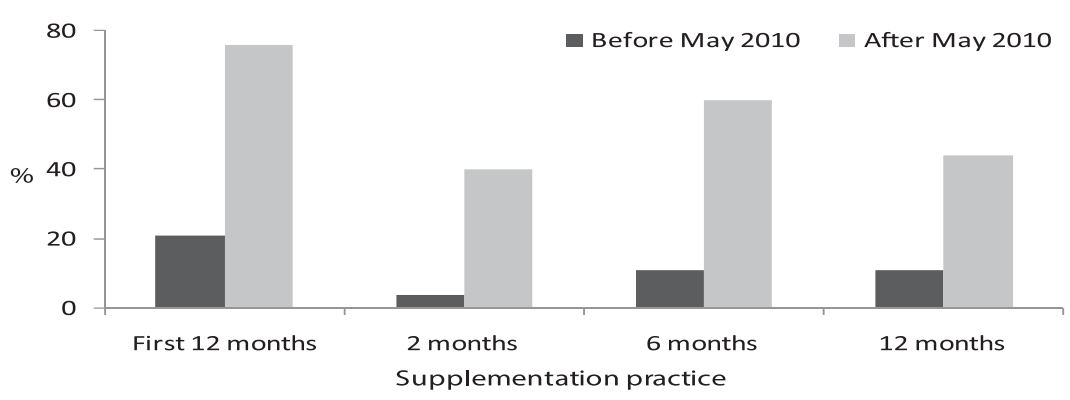

Of those who received a vitamin D supplement at 2, 6 and 12 months, 68,60 and $59 \%$, respectively, were administered $5 \mu \mathrm{g}$ daily. 15 to $24 \%$ gave $5 \mu \mathrm{g}$ 'often' or less than twice during the week. $17 \%$ of infants completely adhered to the policy ( $5 \mu \mathrm{g}$ daily from 0 to 12 months). At all ages, $97 \%$ of mothers provided a vitamin D specific supplement rather than a multi-vitamin, as recommended.

Mothers who used vitamin D-containing supplements during pregnancy $(31 \%)$ were more likely than those who had not $(P<0.001)$ to supplement their infant at 2 months $(60 \mathrm{vs}$. 25\%). Infants who were supplemented at 2 months were more likely to be supplemented at 6 and 12 months $(P<0.001)$. Of those who supplemented at 6 and 12 months, 96 and 88\%, respectively, reported receiving information about supplementation from a healthcare professional.

HSE implementation of the FSAI recommendation to supplement infants with vitamin D had a major impact on supplementation practice. The major determinant of supplementation during year one is an established practice of supplement use during pregnancy and the immediate post-natal period. Currently, maternity hospitals do not have an official policy in place for infant vitamin D supplementation. Continuous evaluation of policy implementation, at a local and national level is important.

This work was supported by the National Children's Research Centre (NCRC).

1. Food Safety Authority of Ireland (2007) http://www.fsai.ie/news_centre/press_releases/16052007.html 